\title{
Comparison of Shunt Active Power Filter Control Strategies for Harmonic Compensation in a Paper Industrial Factory
}

\author{
Mohamed Aboelkasem Mohamd Abdelaal ${ }^{1, ~}$, Mahmoud Abdelnaby Sayed ${ }^{\mathbf{1}}$, \\ Essam E. M. Mohamed ${ }^{1}$, Mohamed Mahmoud Hamada ${ }^{2}$ \\ ${ }^{1}$ Department of Electrical Engineering, South Valley University, Qena, Egypt \\ ${ }^{2}$ Department of Electrical Engineering, Minia University, Minia, Egypt \\ Email address: \\ Mak200500@yahoo.com (M. A. M. Abdelaal), Mahmoud_sayed@ieee.com (M. A. Sayed), \\ esam.mohamed@eng.svu.edu.eg (E. E. M. Mohamed) \\ ${ }^{*}$ Corresponding author
}

\section{To cite this article:}

Mohamed Aboelkasem Mohamd Abdelaal, Mahmoud Abdelnaby Sayed, Essam E. M. Mohamed, Mohamed Mahmoud Hamada. Comparison of Shunt Active Power Filter Control Strategies for Harmonic Compensation in a Paper Industrial Factory. American Journal of Management Science and Engineering. Vol. 2, No. 3, 2017, pp. 41-51. doi: 10.11648/j.ajmse.20170203.12

Received: June 22, 2017; Accepted: July 17, 2017; Published: August 11, 2017

\begin{abstract}
This paper presents the analysis and evaluates different control strategies of shunt active power filters which are used to reduce harmonic distortion created by an industrial paper factory. The model of the whole system has been carried out by Matlab/Simulink. In order to investigate the accuracy of the simulated model, harmonic analysis of simulation results has been compared with measurements from the electrical networks of a Paper Industrial Factory using harmonic analyzer. The consistency of simulation and measured results proves the accuracy of the system modeling. It also proves the validity of using Shunt Active Power Filters to reduce the harmonic distortion in the factory network. Four different control techniques, namely Unit Vector Template Generation, Instantaneous Active and Reactive theory, Synchronous Reference Frame theory and a proposed control strategy that combines the Synchronous Reference Frame and the Unit Vector Template Generation theories, have been studied. Results of each technique were satisfactory and meet the IEEE-519 Standard, However, when the source voltage is distorted the compensation capability for some control strategies is not equal.
\end{abstract}

Keywords: Harmonics, Power Quality, Total Harmonic Distortion, Variable Frequency Drive, Shunt Active Power Filter

\section{Introduction}

The increase of nonlinear loads such as rectifiers, controlled solid-state devices and variable frequency drives causes an increase of harmonic distortion in industrial and power distribution systems. Harmonics are the sinusoidal voltage and currents at frequencies that are integer multiples of fundamental frequency. They have harmful effects on power distribution systems. Therefore, Shunt Active Power Filters (SAPF) is used to eliminate the current harmonics. Current and voltage harmonics are still present in distribution power systems in spite of all efforts made by the electrical equipment manufactures.

Passive filters as one of the harmonic solution have many problems such as resonance, large size and limitation to few harmonic components. On the other hand, shunt active power filters has a better performance than passive filters.

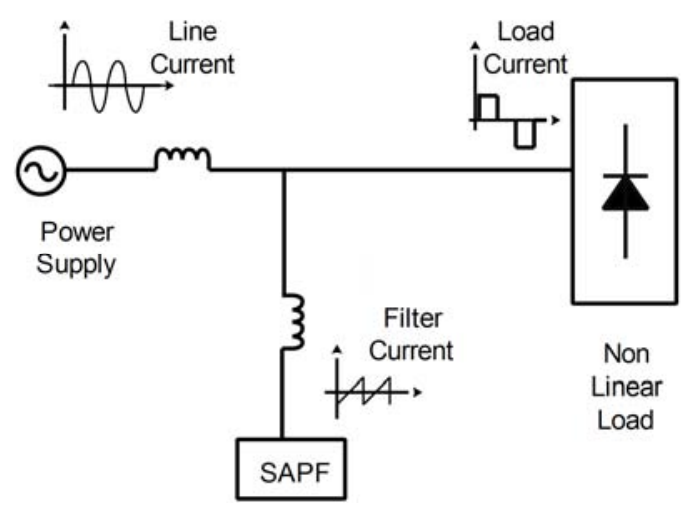

Figure 1. Shunt active filter.

Figure 1 shows operation principle of shunt active filter and how can it compensates the input current by monitoring the distortion of the input current and injects the same distortion 
quantities at the input side with 180 degree phase shift. Hence harmonic contained in the load current are cancelled at the source side. Therefore, the load current still has the necessary harmonic contents, whereas the source current remains sinusoidal.

The control scheme of a shunt active power filter usually includes calculation of the reference current required to compensate the input current, maintain constant voltage across the DC (Direct Current) link capacitor, and generate the inverter PWM (Pulse Width Modulation) gate signals.

This paper presents the implementation of shunt active power filters to reduce the harmonic distortion created by a paper industrial factory. The factory model and the shunt active filter have been carried out using Matlab/Simulink. The reference current of the shunt active filter has been calculated using four different control strategies, namely;

a) Unit Vector Template Generation (UVTG) b) Instantaneous Active and Reactive (P-Q) theory

c) Synchronous Reference Frame (SRF)

d) proposed control strategy that is combined between P-Q and UVTG theory

Simulation results of the paper industrial factory model have been compared with the actual results to show the accuracy of the simulation model.

\section{Harmonic Limits}

The acceptable levels of harmonics are determined using international standards such as the IEEE 519-2014, which has the permissible voltage and current harmonics in industrial systems applications. The current harmonic limits depend on the ratio of short circuit current $\left(\mathrm{I}_{\mathrm{sc}}\right)$ to maximum load current $\left(\mathrm{I}_{\text {load }}\right)$ at common coupling point as given in Table 1 [1]:

Table 1. Current Harmonic Limits as per IEEE 519-2014 [1].

\begin{tabular}{|c|c|c|c|c|c|c|}
\hline \multicolumn{7}{|c|}{ Individual harmonic order (Odd harmonics) } \\
\hline Isc / Iload & $<11$ & $\mathbf{1 1} \leq \mathrm{h}<\mathbf{1 7}$ & $17 \leq h<23$ & $23 \leq h<35$ & $35 \leq h$ & TDD \\
\hline$<20$ & 4.0 & 2.0 & 1.5 & 0.6 & 0.3 & 5.0 \\
\hline $20<50$ & 7.0 & 3.5 & 2.5 & 1.0 & 0.5 & 8.0 \\
\hline $50<100$ & 10.0 & 4.5 & 4.0 & 1.5 & 0.7 & 12.0 \\
\hline $100<1000$ & 12.0 & 5.5 & 5.0 & 2.0 & 1.0 & 15.0 \\
\hline$>1000$ & 15.0 & 7.0 & 6.0 & 2.5 & 1.4 & 20.0 \\
\hline
\end{tabular}

Where, $\mathrm{h}$ is individual harmonic order and TDD is total demand distortion.

The limitation of even harmonics is $25 \%$ of odd harmonic limits in Table 1.

\section{Control Algorithms}

\subsection{Instantaneous $P-Q$ Theory Control}

Figure 2 shows the block diagram of the shunt active filter based on the P-Q theory introduced by Akagi in 1983 [2], [3], [4], [5], [6].

The three phase voltages $\left(\mathrm{V}_{\mathrm{abc}}\right)$ and currents $\left(\mathrm{i}_{\mathrm{Labc}}\right)$ are transformed from the a-b-c coordinates to $\alpha-\beta-0$ coordinates using Clarke transformation as in (1) and (2).

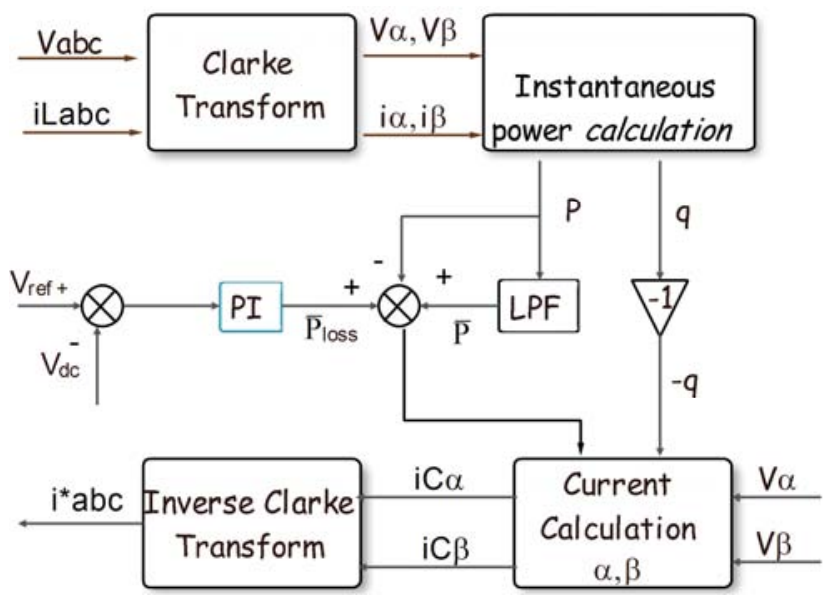

Figure 2. Block diagram of the shunt active filter based on the $P-Q$ theory.

$$
\left[\begin{array}{c}
v \alpha \\
v \beta
\end{array}\right]=[T]\left[\begin{array}{l}
V_{a} \\
V_{b} \\
V_{c}
\end{array}\right]
$$

$$
\left[\begin{array}{c}
i \alpha \\
i \beta
\end{array}\right]=[T]\left[\begin{array}{l}
i L a \\
i L b \\
i L_{c}
\end{array}\right]
$$

Where $\mathrm{T}$ is expressed as follows:

$$
T=\sqrt{\frac{2}{3}}\left[\begin{array}{ccc}
1 & -\frac{1}{2} & -\frac{1}{2} \\
0 & \frac{\sqrt{3}}{2} & -\frac{\sqrt{3}}{2}
\end{array}\right]
$$

The instantaneous active and reactive power can be formulated as (4).

$$
\left[\begin{array}{l}
p \\
q
\end{array}\right]=A \times\left[\begin{array}{l}
i \alpha \\
i \beta
\end{array}\right]
$$

Where,

$$
\begin{gathered}
A=\left[\begin{array}{cc}
v \alpha & v \beta \\
v \beta & -v \alpha
\end{array}\right] \\
p=\bar{p}+\tilde{p} \\
q=\bar{q}+\tilde{q}
\end{gathered}
$$


Whe e $\tilde{p}$ and $\tilde{q}$ represent the oscillating powers and $\overline{\mathrm{p}}$ and $\overline{\mathrm{q}}$ represent the average powers. A low pass filter is used to separate between $\overline{\mathrm{p}}$ and $\tilde{q}$. r.

Compensation current references in the $(\alpha-\beta)$ reference frame can be expressed as:

$$
\left[\begin{array}{l}
i c \alpha \\
i c \beta
\end{array}\right]=\frac{1}{v \alpha_{2}+v \beta 2} \times A \times B
$$

Where,

$$
B=\left[\begin{array}{c}
-\tilde{p}+\bar{p} \text { loss } \\
-q
\end{array}\right]
$$

$\bar{P}_{\text {loss }}$ is the PI (Proportional Integral) controller output of the dc-link capacitor voltage error. It represents the small real power taken continuously from the power supply to maintain the dc capacitor voltage constant. The compensation current references in the three-phase frame can be obtained as follows:

$$
\left[\begin{array}{c}
I_{a}^{*} \\
I_{b}^{*} \\
I_{c}^{*}
\end{array}\right]=\sqrt{\frac{2}{3}} \times T_{i n v} \times\left[\begin{array}{c}
i c \alpha \\
i c \beta
\end{array}\right]
$$

Where,

$$
T_{i n v}=\left[\begin{array}{cc}
1 & 0 \\
-\frac{1}{2} & \frac{\sqrt{3}}{2} \\
-\frac{1}{2} & -\frac{\sqrt{3}}{2}
\end{array}\right]
$$

\subsection{Unit Vector Template Generation Technique}

Figure 3 shows the block diagram of the shunt active filter based on the UVTG theory [7], [8], [9], [10]. In this strategy the supply voltage is sensed and given to the Phase Locked Loop (PLL) and with a proper phase delay the outputs of the Unit Vector Templates $\left(X a, X_{b}\right.$ and $\left.X_{C}\right)$ can be expressed as (12).

$$
\begin{aligned}
& X a=\sin (w t) \\
& X_{b}=\operatorname{Sin}(w t-120) \\
& X_{C}=\operatorname{Sin}(w t+120)
\end{aligned}
$$

The PI control is used to maintain the dc-link voltage constant by comparing the DC voltage reference and the actual dc-link voltage. The output error is multiplied by the output of Unit Vector Templates, which gives the reference source current signals as (13).

$$
\left[\begin{array}{c}
I_{a}^{*} \\
I_{b}^{*} \\
I_{c}^{*}
\end{array}\right]=\operatorname{Im}\left[\begin{array}{c}
X_{a} \\
X_{b} \\
X_{c}
\end{array}\right]
$$

The actual source current is compared with the reference current signal and the output is applied to a hysteresis current controller that generates the switching signals of the shunt active filter inverter.

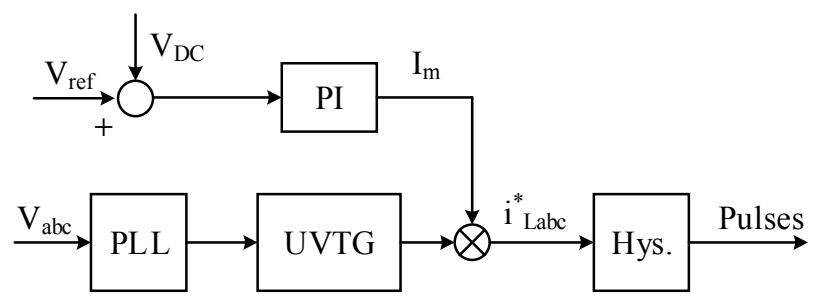

Figure 3. Control block of the shunt active filter based on UVTG theory.

\subsection{Synchronous Reference Frame Technique}

Figure 4 shows the block diagram of the shunt active filter based on synchronous reference frame theory or d-q theory [11], [12], and [13]. In this technique, the load current is transformed to the $\mathrm{d}-\mathrm{q}$ synchronous reference coordinate using Park Transform as per the following equation:

$$
\left[\begin{array}{c}
i d \\
i_{q} \\
i 0
\end{array}\right]=\frac{2}{3} \times K \times\left[\begin{array}{c}
i L a \\
i L b \\
i L_{c}
\end{array}\right]
$$

Where,

$$
K=\left[\begin{array}{ccc}
\cos (w t) & \cos \left(w t-\frac{2 \Pi}{3}\right) & \cos \left(w t+\frac{2 \Pi}{3}\right) \\
-\sin (w t) & -\sin \left(w t-\frac{2 \Pi}{3}\right) & -\sin \left(w t+\frac{2 \Pi}{3}\right) \\
\frac{1}{2} & \frac{1}{2} & \frac{1}{2}
\end{array}\right]
$$

Low Pass Filter (LPF) is used to separate the harmonic reference current from the load current. The PI controller is used to maintain the dc-link voltage constant.

PLL is applied to develop the electrical position $(\theta)$ which helps to maintain synchronism of the supply voltage and current.

The current source reference can be obtained in three-phase system using inverse Park Transform as per the following equation:

$$
\left[\begin{array}{c}
I_{a}^{*} \\
I_{b}^{*} \\
I_{c}^{*}
\end{array}\right]=K_{i n v} \times\left[\begin{array}{c}
i d \\
i q \\
i 0
\end{array}\right]
$$

Where, 


$$
K_{i n v}=\left[\begin{array}{ccc}
\cos (w t) & -\sin (w t) & 1 \\
\cos \left(w t-\frac{2 \Pi}{3}\right) & -\sin \left(w t-\frac{2 \Pi}{3}\right) & 1 \\
\cos \left(w t+\frac{2 \Pi}{3}\right) & -\sin \left(w t+\frac{2 \Pi}{3}\right) & 1
\end{array}\right]
$$

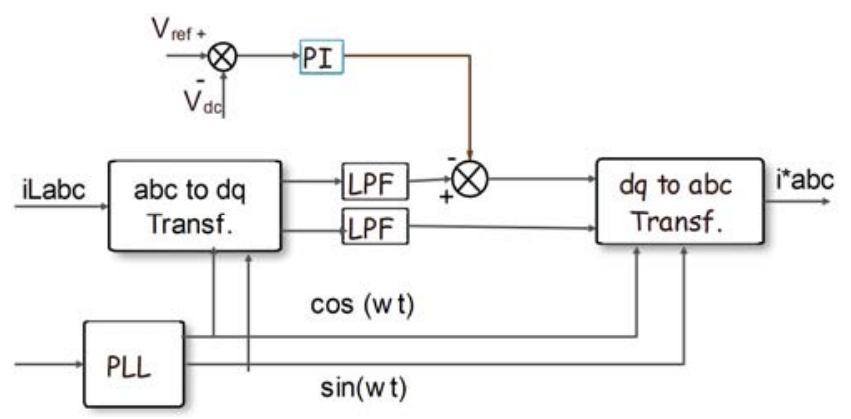

Figure 4. Control block of the Shunt active filter based on d-q strategy.

\subsection{Combined P-Q Theory and UVTG Theory}

When the source voltage is distorted, the compensation current of conventional P-Q control strategy will not be sinusoidal. This section proposes a combined P-Q and UVTG control strategy as shown in Figure 5.

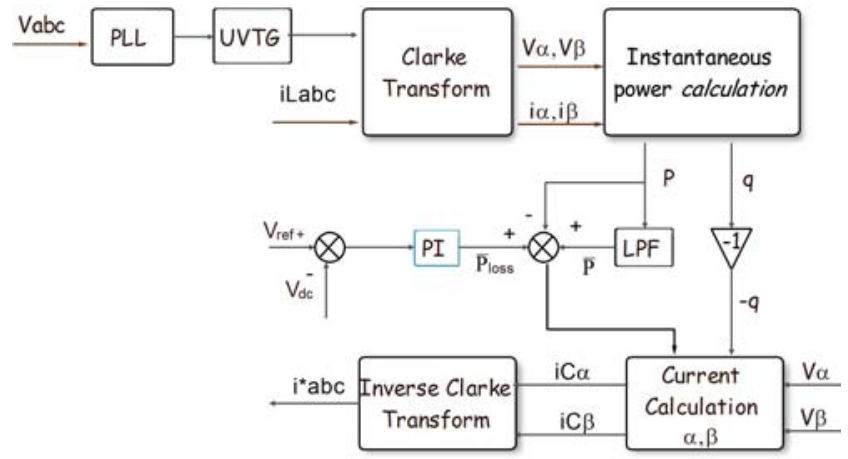

Figure 5. Block diagram based on combined $P-Q$ and UVTG Theories.

The idea is to eliminate the distortion in the supply voltage before applying to the conventional P-Q control strategy.

To achieve this target, the distorted supply voltage is applied to PLL. The UVTG is used to compute the supply unit vectors ( $X a, X b$ and $X_{C}$ ) as in Equation (12). The three-phase voltage references are calculated by (18), where $(\mathrm{Vm})$ is the peak value of the fundamental voltage.

$$
\left[\begin{array}{c}
V_{a}^{*} \\
V_{b}^{*} \\
V_{c}^{*}
\end{array}\right]=V m\left[\begin{array}{c}
X a \\
X b \\
X_{c}
\end{array}\right]
$$

The remaining block diagram will be the same as explained in section (3.1).

\section{Case Study Paper Industrial Factory}

Simulation for one of paper factory (Qena Paper Industry) in Egypt has been carried out by MATLAB. Figure 6 shows the single line diagram of the factory electrical network that consists of the following main transformers:

a) Transformers No. BAT 01 to BAT 06 feed constant speed motors.

b) Transformers No. BAT07 and BAT08 feed two 6-pules diode rectifiers, which feed different $\mathrm{AC}$ induction motors through DC-AC inverters.

c) Transformers No. BAT09 and BAT10 feed three 6-pulse Thyristor rectifiers, which feed different $\mathrm{AC}$ induction motors through DC-AC inverters

As an example the results of transformer No. BAT 07 with its nonlinear loads as shown in Figure 7.

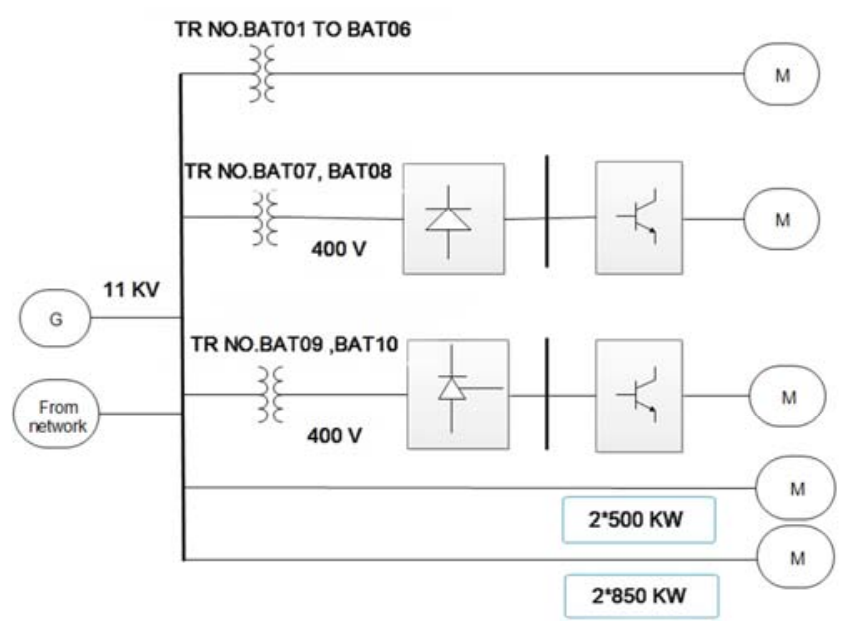

Figure 6. Single line diagram of the paper factory.

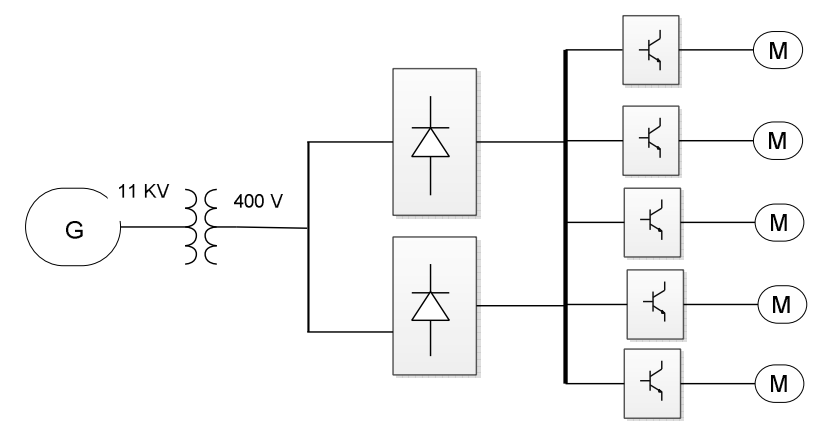

Figure 7. Single line diagram of Transformer No. BAT07 and motor loads.

Actual measurements using harmonic analyzer were recorded as shown in Table 2. A printout of the results is shown in Appendix 2.

Table 2. Actual measurements for transformer NO BAT07 L. V side.

\begin{tabular}{lllllllllll}
\hline H & $\mathbf{3}$ & $\mathbf{5}$ & $\mathbf{7}$ & $\mathbf{9}$ & $\mathbf{1 1}$ & $\mathbf{1 3}$ & $\mathbf{1 5}$ & $\mathbf{1 7}$ & $\mathbf{1 9}$ & $\mathbf{2 1}$ \\
\hline$\%$ & 2.6 & 29.21 & 7.43 & 0.36 & 5.37 & 3.56 & 0.72 & 1.23 & 1.12 & 0.76 \\
THD & $29.8 \%$ & & & & & & & & & \\
\hline
\end{tabular}




\section{Simulation Results}

Table 3. THD of Case (A).

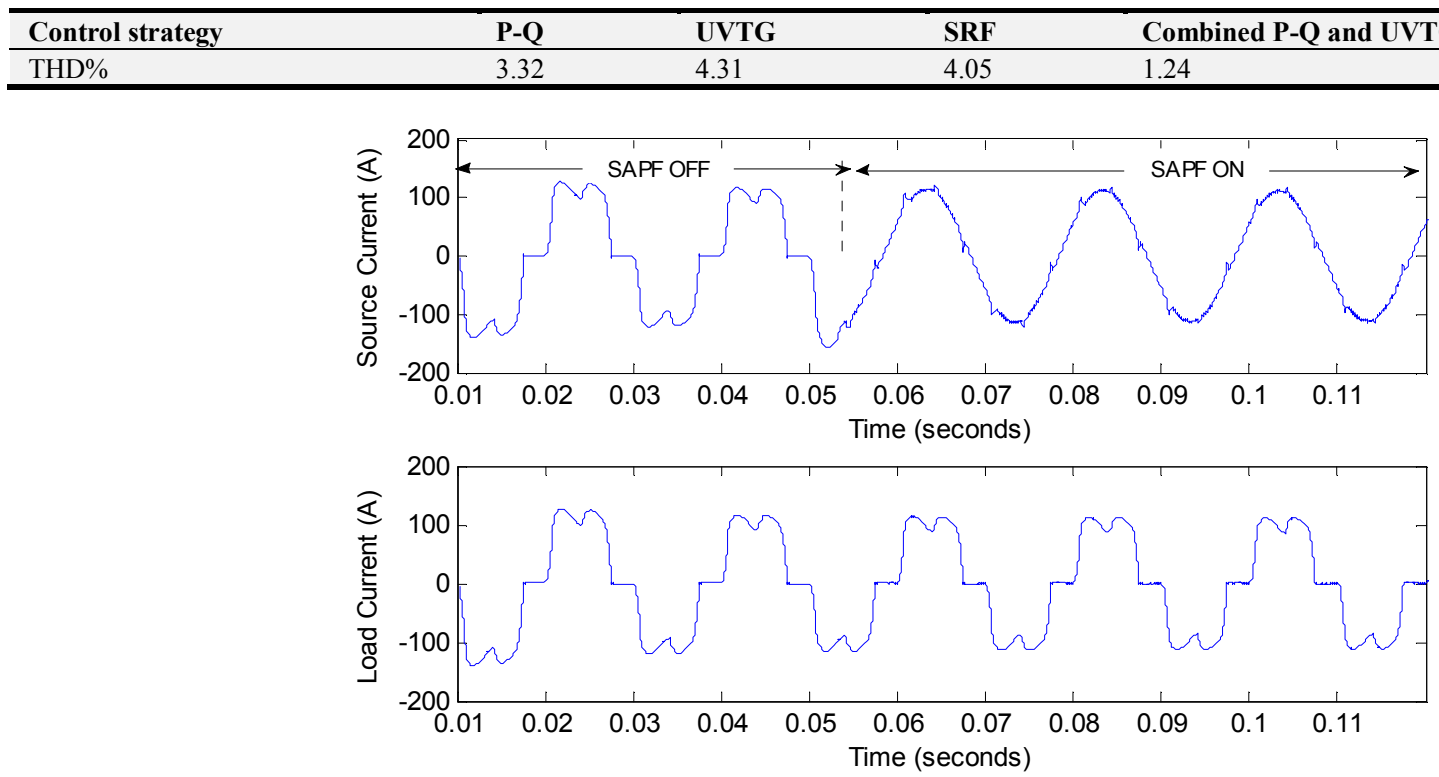

(a) P-Q theory
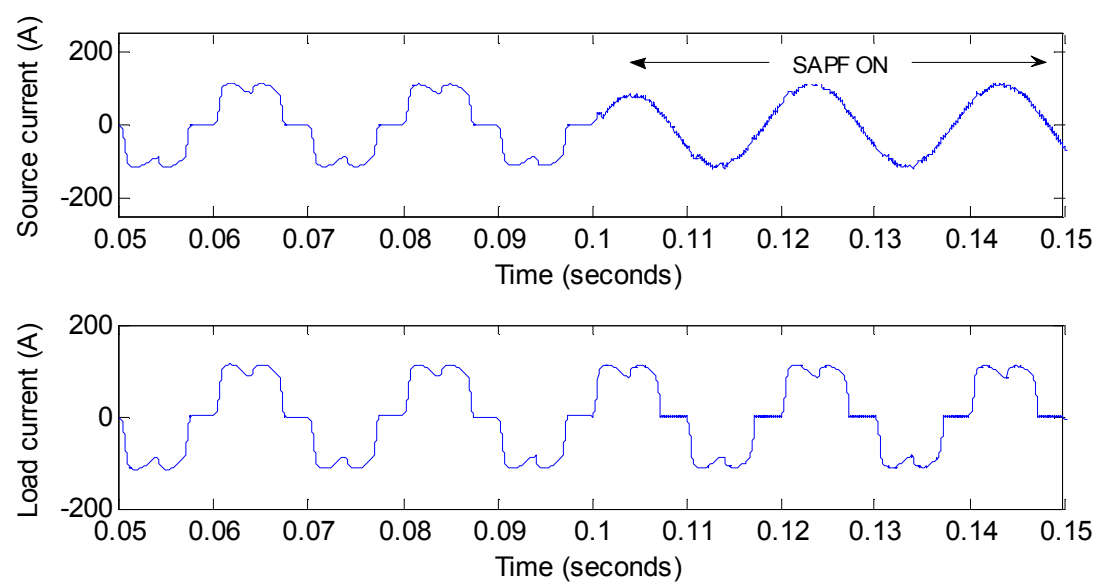

(b) UVTG theory
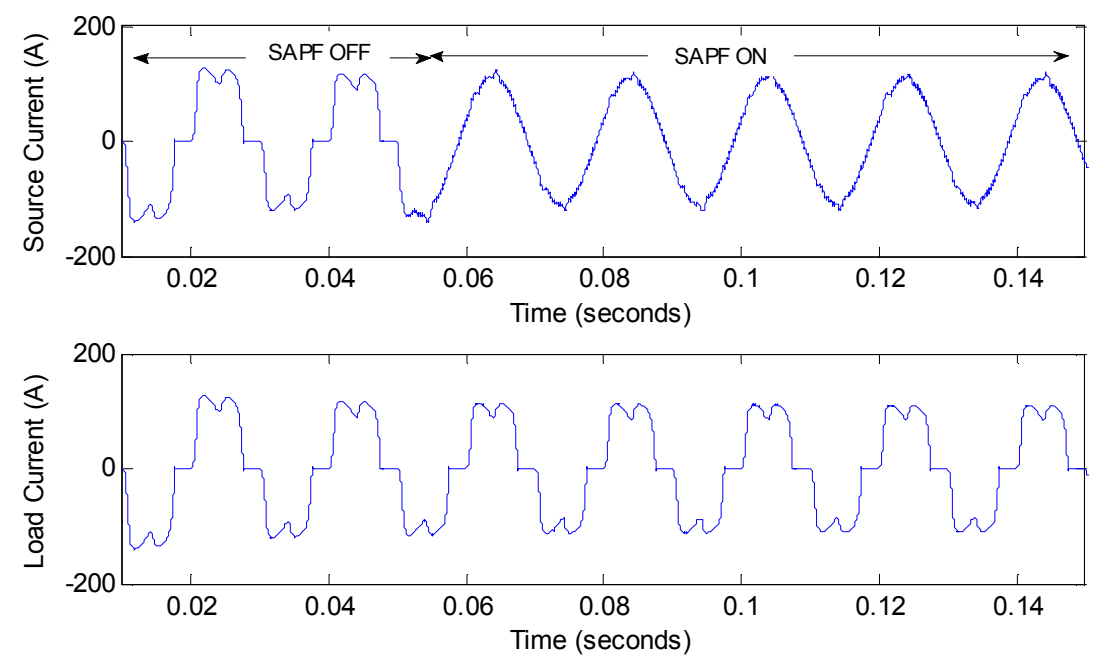

(c) d-q strategies 

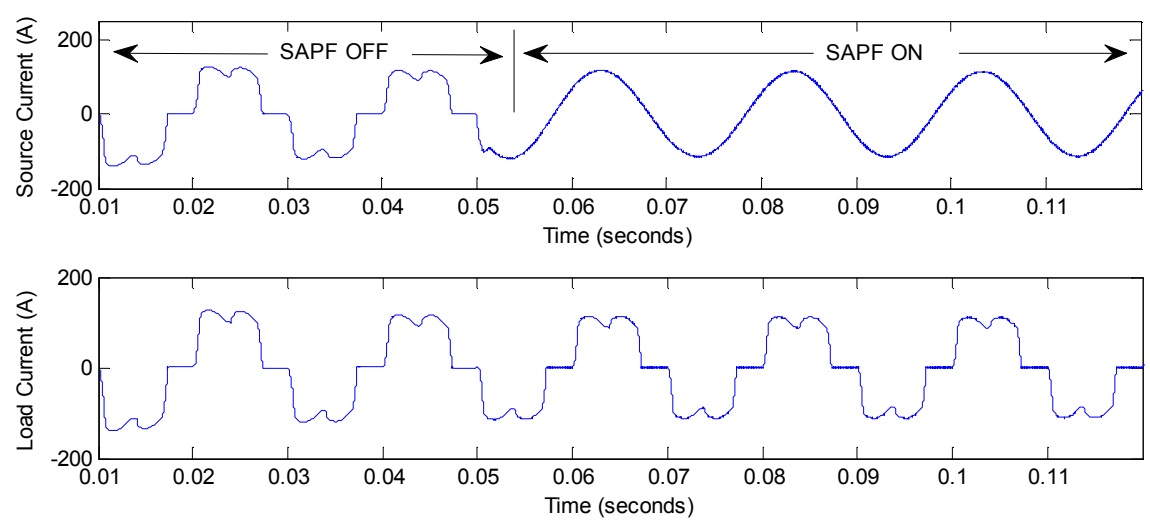

(d) Combined P-Q and UVTG Theory

Figure 8. Simulation Results for case (A) source and load current.

The complete model of shunt active filter is shown in Appendix 1. For comparison between different control strategies, simulation under ideal and distorted voltage source have been carried out.

Case (A): Ideal Source Voltage

The Ideal source Voltage case happens at the factory when it is connected to its own power plant.

Figure 8 show the simulation results for source and load current of SAPF control before and after compensation.

Figure 9 shows Frequency spectrum. THD (Total Harmonic Distortion) levels of the source current after applying the SPAF is given in Table 3. It can be seen that the THD has been reduced from $27.87 \%$ to the IEEE 519-1992 Limits when the SAPF is applied for all the studied techniques, however the combined P-Q and UVTG theory exhibits the lowest THD of $1.24 \%$.

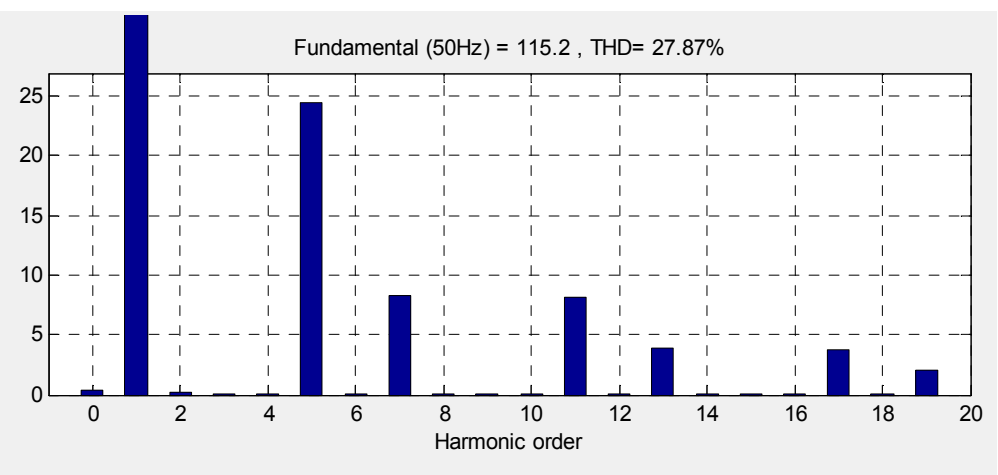

(a) Load Current

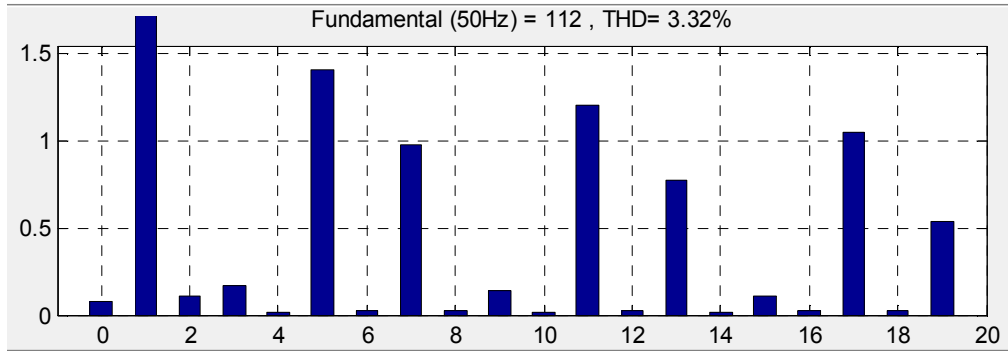

(b) P-Q theory

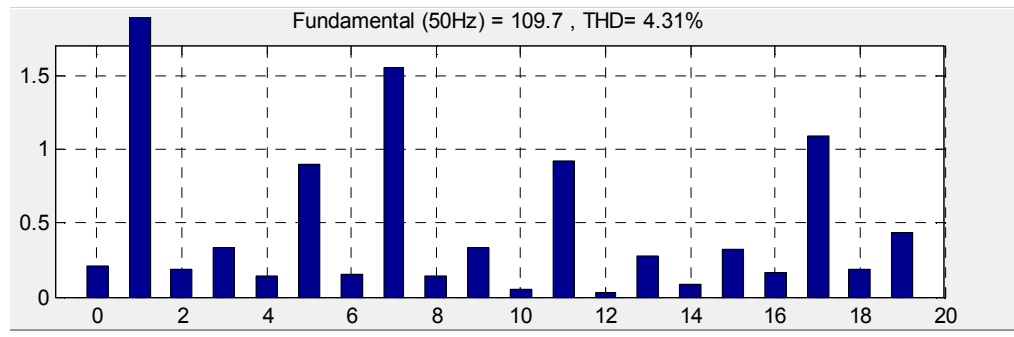

(c) UVTG theory 


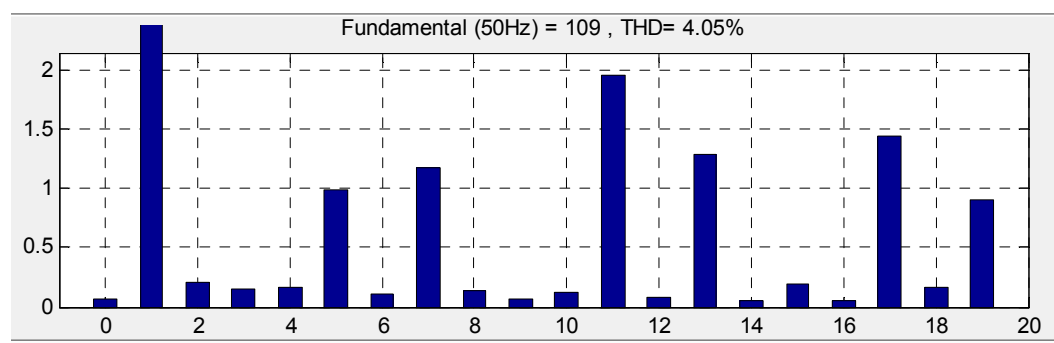

(d) d-q theory

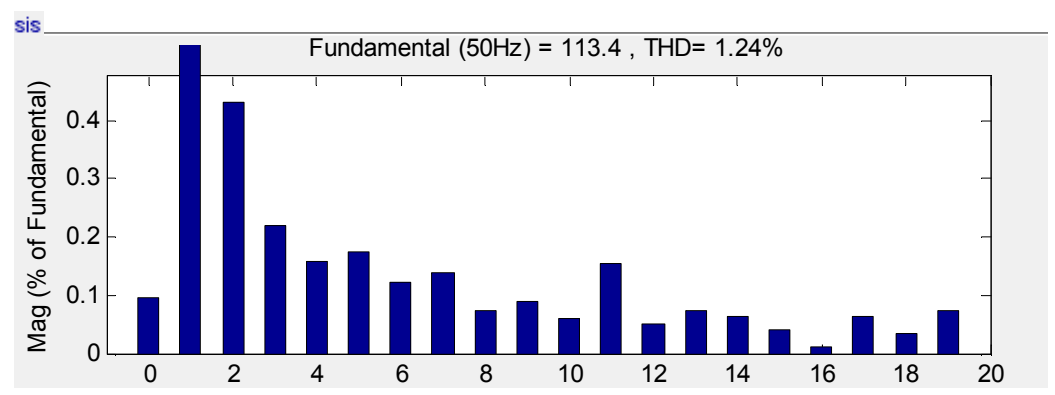

(e) Combined P-Q and UVTG Theory

Figure 9. Case (A) Frequency spectrum.

Case (B): distorted voltage source

The distorted supply voltage case is happened when the factory is connected to the Electrical network in case of its own power plant is under maintenance or breakdown which observed that it has mainly harmonic orders $5^{\text {th }}$ and $7^{\text {th }}$.

The simulation of distortion in supply voltage at this condition with a value of harmonic order $5^{\text {th }}(20 \%$ of the fundamental input) and $7^{\text {th }}$ (5\% of fundamental input) harmonic voltage sources was done as shown in Figure 10.

Figures 11 show the simulation results for source and load current of SAPF control before and after compensation.

Figure 12 shows Frequency spectrum.

A summary of the results are shown in Table 4.

Table 4. Simulation result in case B distorted supply Voltage.

\begin{tabular}{lllll}
\hline Control strategy & P-Q & UVTG & d-q & Combined P-Q and UVTG Theory \\
\hline THD & $22.10 \%$ & $4.81 \%$ & $24.07 \%$ & $3.87 \%$ \\
\hline
\end{tabular}

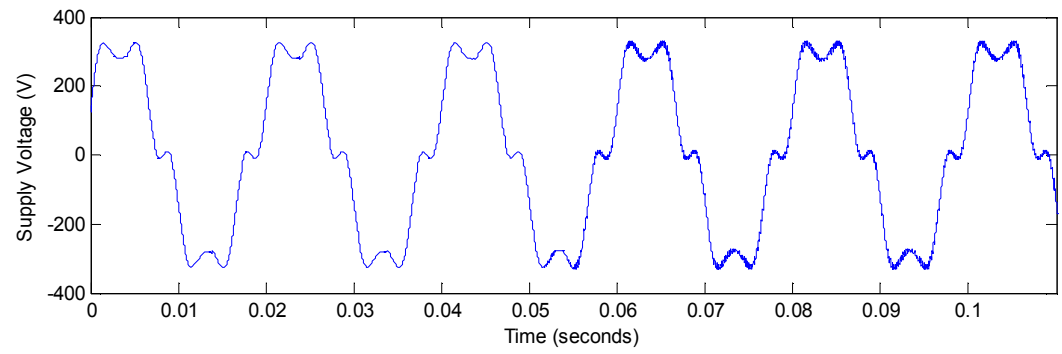

Figure 10. Distorted Supply voltage.
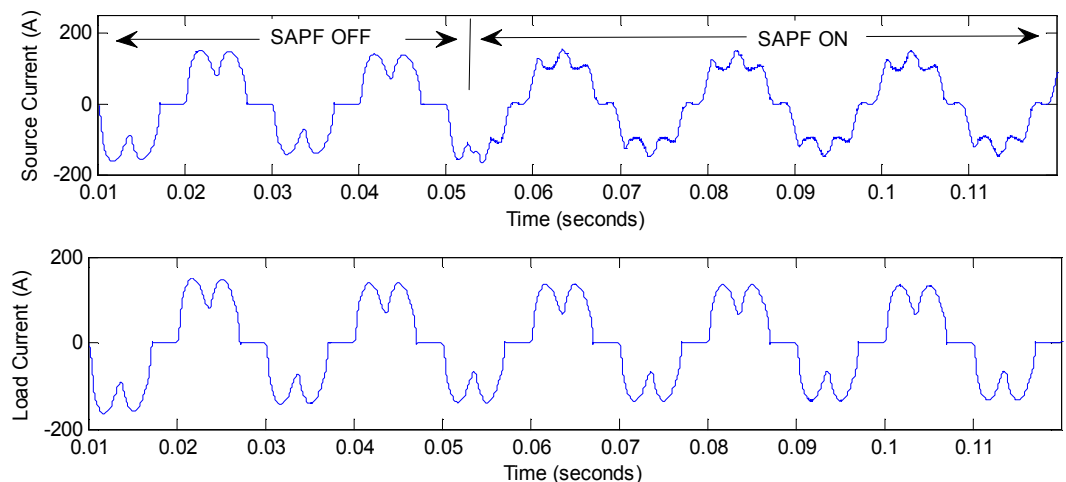

(a) P-Q theory 

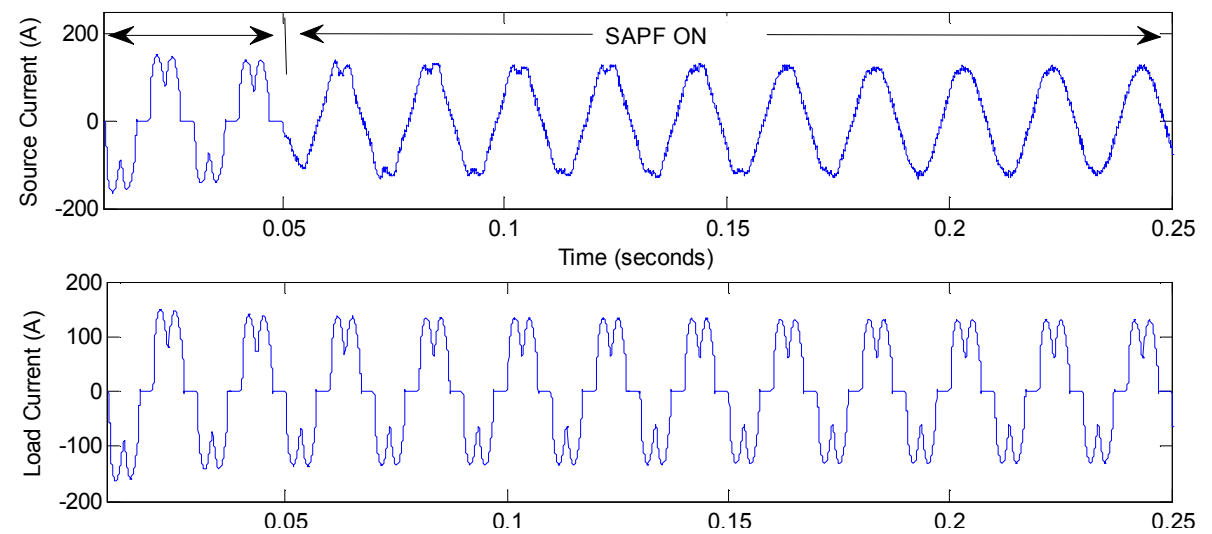

(b) UVTG theory
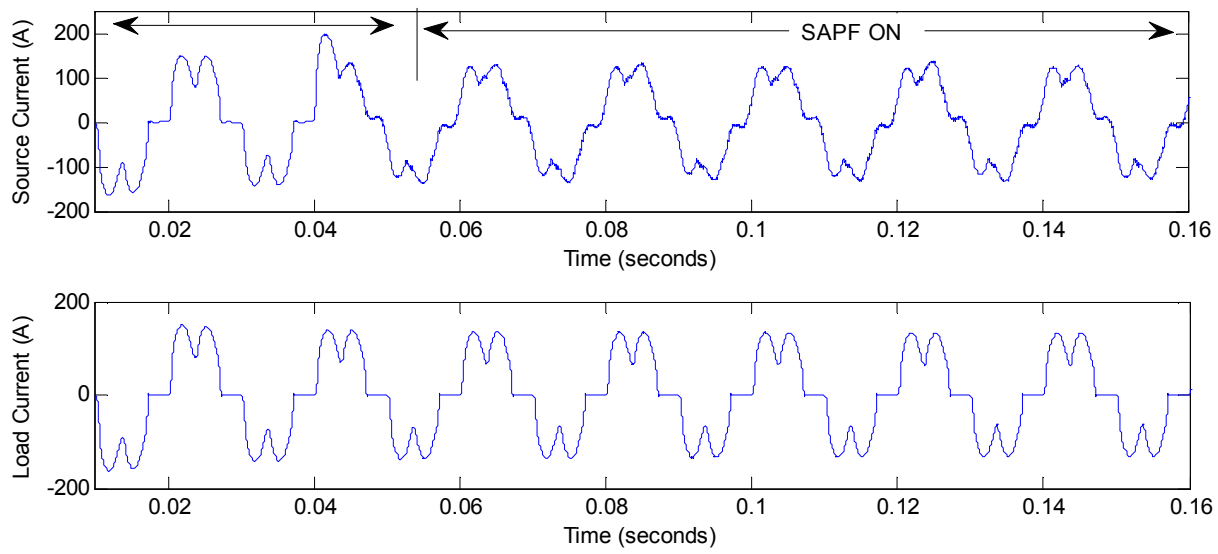

(c) d-q strategies
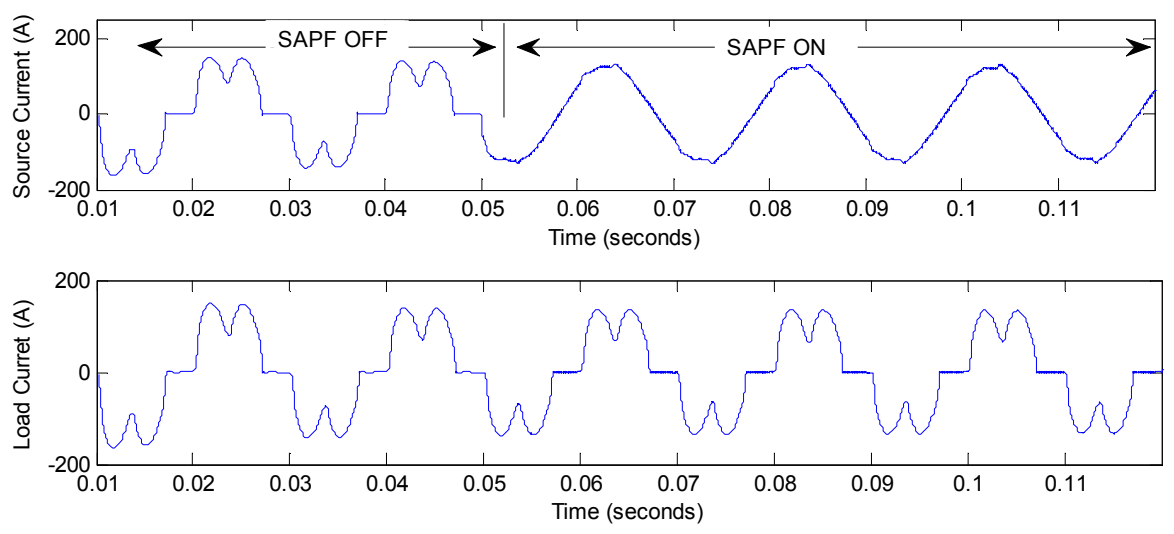

(d) Combined P-Q and UVTG Theory

Figure 11. Simulation Results for case (B) source and load current.

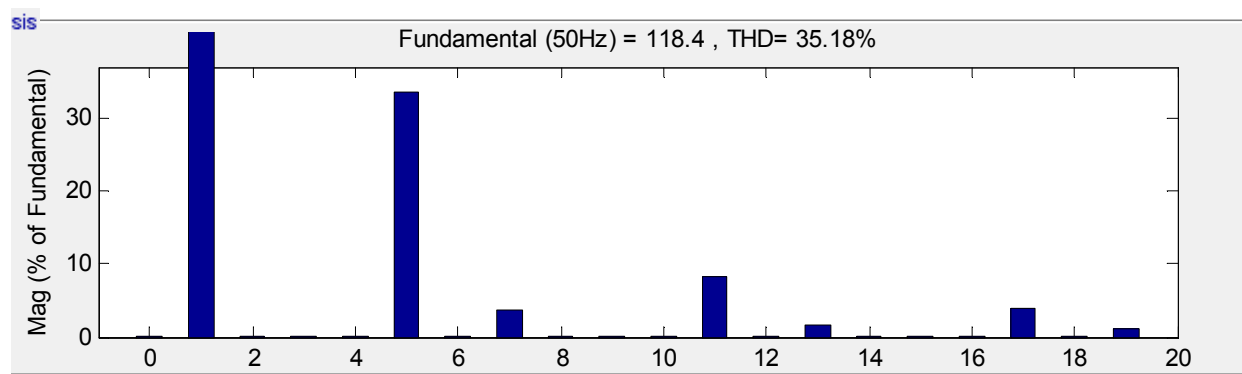

(a) Load Current 


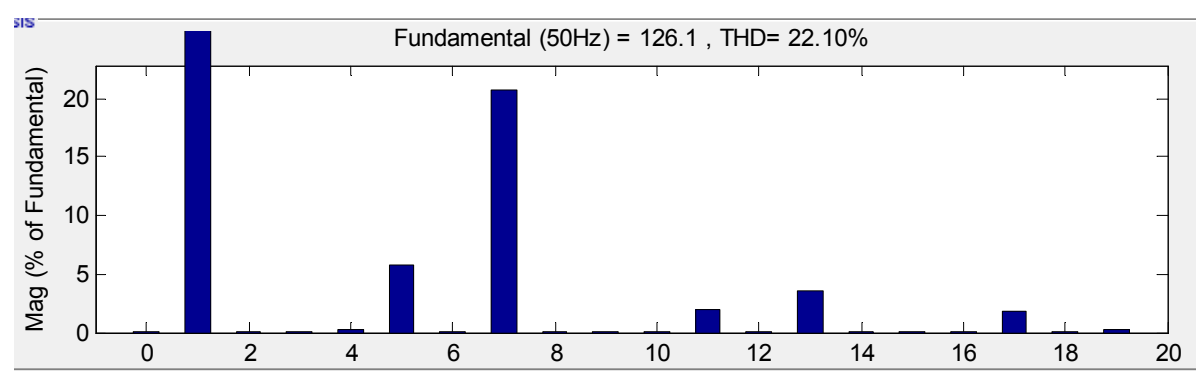

(b) P-Q theory

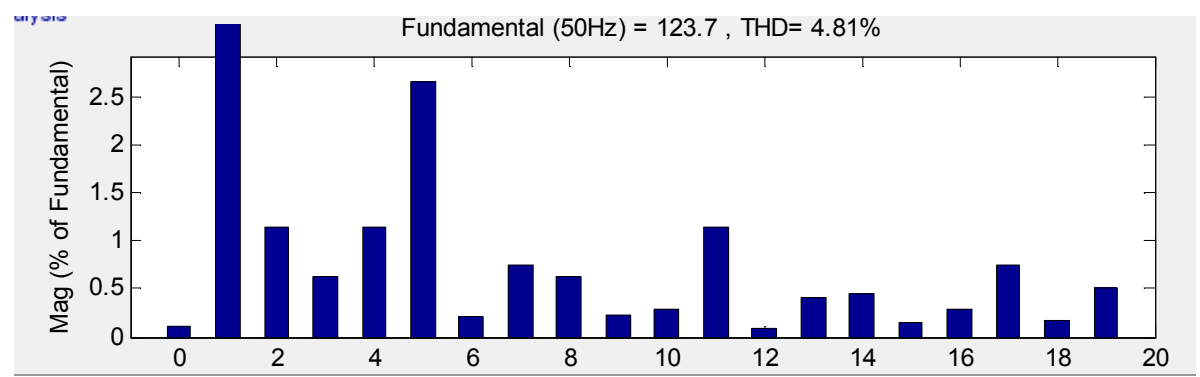

(c) UVTG theory

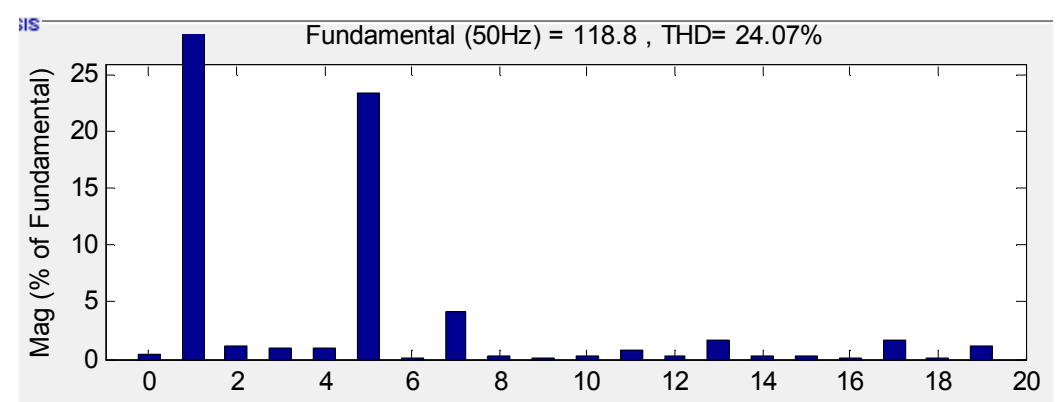

(d) d-q theory

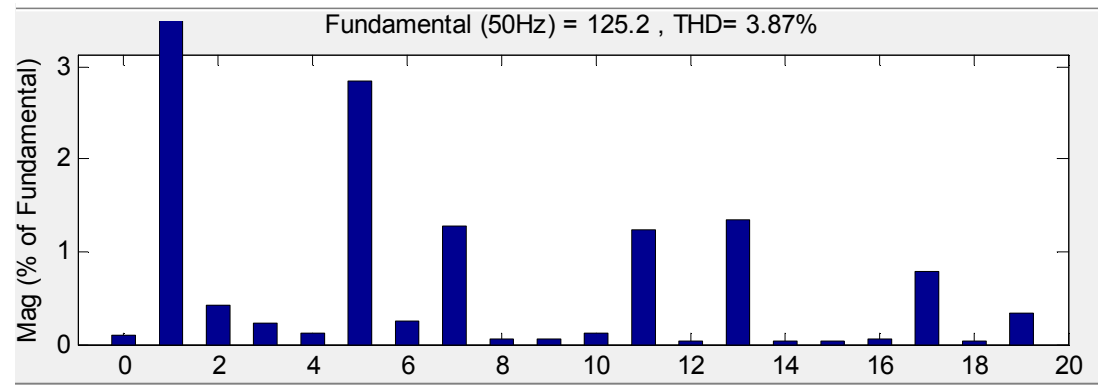

(e) Combined P-Q and UVTG Theory

Figure 12. Case (B) Frequency spectrum.

The THD level of the source current was reduced from $35.18 \%$ to $22.10 \%, 4.81 \%, 24.07 \%$ and $3.87 \%$ by using P-Q, UVTG, SRF and combined (P-Q and UVTG) control strategy respectively.

It is clear that from the simulation results that in the presence of distorted mains voltage P-Q and $\mathrm{d}-\mathrm{q}$ control strategy are given poor results in terms of THD, however UVTG and the proposed topology Combined P-Q and UVTG Theory are given satisfactory results, and The proposed control strategy combined P-Q and UVTG strategy has the least THD value result for the source current.

\section{Conclusion}

This paper presents modeling and design of shunt active filter along with different control techniques for minimizing harmonics of Qena Paper Industry factory. Shunt active power filter based on four different control strategies namely, the P-Q theory, the Unit Vector Template Generation theory, the Synchronous Reference Frame theory and the proposed combined P-Q and UVTG theory has been simulated under ideal and distorted supply voltage 
conditions. The simulation results show that the fur techniques effectively compensate the harmonics. The THD of Qena Paper Industry factory is reduced to the permissible limits according to the IEEE-519 Standards under ideal supply voltage condition for all the control strategies. The P-Q and SRF control strategies are very sensitive to the distortion in the supply voltage. The UVTG theory and the combined P-Q and UVTG strategy are capable of compensating harmonic currents under the two cases; however the combined P-Q and UVTG strategy has the lowest THD for the source current.

\section{Appendix}

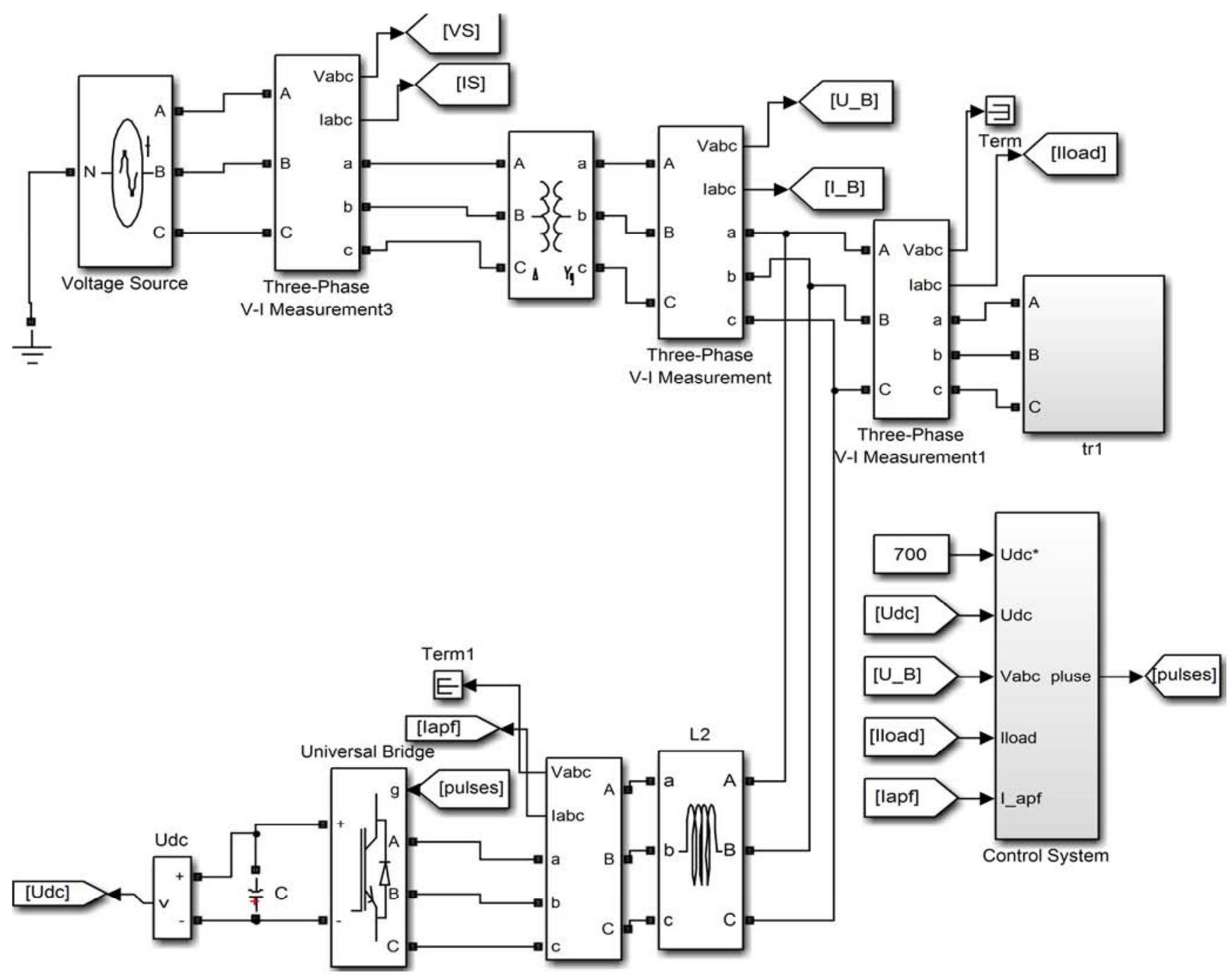

Appendix 1. System Model with Shunt Active Power Filter.

\begin{tabular}{|l|l|l|l|l|}
\hline H. & MODULE & H. & MODULE & PF:0.957 \\
\hline DC & $1.55 \%$ & 21 & $0.76 \%$ & \\
3 & $2.61 \%$ & 23 & $1.12 \%$ & F:49.9 HZ \\
5 & $29.21 \%$ & 25 & $1.55 \%$ & \\
7 & $7.43 \%$ & 27 & $0.20 \%$ & V:405V \\
9 & $0.36 \%$ & 29 & $0.73 \%$ & \\
11 & $5.37 \%$ & 31 & $0.34 \%$ & I :166A \\
13 & $3.56 \%$ & 33 & $0.35 \%$ & \\
15 & $0.72 \%$ & 35 & $0.52 \%$ & THD :29.81\% \\
17 & $1.23 \%$ & 37 & $0.35 \%$ & print \\
19 & 1.12 & 39 & $0.99 \%$ & $\mathbf{1 0 : 3 1}$ \\
& & & &
\end{tabular}

Appendix 2. Print out of the harmonic analyzer.

\section{References}

[1] IEEE Standards Association, IEEE Std 519-2014-Recommended Practice and Requirements for Harmonic Control in Electric Power Systems. IEEE Power and Energy Society, 29.

[2] Akagi, H., Watanabe, E. H. and Aredes, M., 2017. Instantaneous power theory and applications to power conditioning. John Wiley \& Sons.

[3] Mortezaei, A., Lute, C., Simoes, M. G., Marafão, F. P. and Boglia, A., 2014, September. PQ, DQ and CPT control methods for shunt active compensators - A comparative study. In Energy Conversion Congress and Exposition (ECCE), 2014 IEEE (pp. 2994-3001). IEEE. 
[4] Soares, V., Verdelho, P. and Marques, G. D., 2000. An instantaneous active and reactive current component method for active filters. IEEE Transactions on Power Electronics, 15 (4), pp.660-669.

[5] UdayaSri, B., Rao, P. M., Mohanta, D. K. and Varma, M. P. C., 2016, October. Improvement of power quality using PQ-theory shunt-active power filter. In Signal Processing, Communication, Power and Embedded System (SCOPES), 2016 International Conference on (pp. 2083-2088). IEEE.

[6] Montes, A. O. and Ramos, G., 2013, July. Instantaneous pq theory for harmonic compensation via shunt active power filter. In Power Electronics and Power Quality Applications (PEPQA), 2013 Workshop on (pp. 1-4). IEEE.

[7] Gohil, S. N., Makwana, M. V., Kadivar, K. T. and Tetar, G. J., 2013, December. Three phase unified power quality conditioner (UPQC) for power quality improvement by using UVTG technique. In Renewable Energy and Sustainable Energy (ICRESE), 2013 International Conference on (pp. 151-156). IEEE.

[8] Pal, Yash, A. Swarup, and B. Singh. "A New Topology of Three-Phase Four-Wire UPQC with a Simplified Control Algorithm." Majlesi Journal of Electrical Engineering 6.1 (2012).
[9] Prathyusha, D. and Venkatesh, P., 2015. UVTG Control Strategy for Three Phase Four Wire UPQC to Improve Power Quality. Int. Electr. Eng. J, 6 (9), pp. 1988-1993.

[10] Sundarabalan, C. K. and Sathishbabu, P., 2012. Unified Power Quality Conditioner for Enhancement of Power Quality and Hybrid Power Generation Injection to Grid. International Journal of Modern Engineering Research (IJMER), 2 (2).

[11] Vora, S., Bhatt, D. H. and Thakar, J. B., 2014. Comparative study on different control strategies using shunt active power filter for current harmonics mitigation. International Journal For Technological Research In Engineering, 1 (10), pp. 2347-4718.

[12] Samal, S., Hota, P. K. and Barik, P. K., 2016, October. Harmonics mitigation by using shunt active power filter under different load condition. In Signal Processing, Communication, Power and Embedded System (SCOPES), 2016 International Conference on (pp. 94-98). IEEE.

[13] Kumari, N. and Awashthi, I., 2013. Harmonic Compensation Using Shunt Active Power Filter in Power System Using Matlab. International Journal of Scientific Engineering and Research, 1 (3). 